\title{
Online measurements of the emissions of intermediate-volatility and semi-volatile organic compounds from aircraft
}

\author{
E. S. Cross ${ }^{1}$, J. F. Hunter ${ }^{1}$, A. J. Carrasquillo ${ }^{1}$, J. P. Franklin ${ }^{1}$, S. C. Herndon ${ }^{3}$, J. T. Jayne ${ }^{3}$, D. R. Worsnop ${ }^{3}$, \\ R. C. Miake-Lye ${ }^{3}$, and J. H. Kroll ${ }^{1,2}$ \\ ${ }^{1}$ Department of Civil and Environmental Engineering, Massachusetts Institute of Technology, Cambridge, MA, USA \\ ${ }^{2}$ Department of Chemical Engineering, Massachusetts Institute of Technology, Cambridge, MA, USA \\ ${ }^{3}$ Aerodyne Research, Inc., Billerica, MA, USA
}

Correspondence to: J. H. Kroll (jhkroll@mit.edu)

Received: 12 March 2013 - Published in Atmos. Chem. Phys. Discuss.: 25 March 2013

Revised: 5 July 2013 - Accepted: 8 July 2013 - Published: 14 August 2013

\begin{abstract}
A detailed understanding of the climate and air quality impacts of aviation requires measurements of the emissions of intermediate-volatility and semi-volatile organic compounds (I/SVOCs) from aircraft. Currently both the amount and chemical composition of aircraft I/SVOC emissions remain poorly characterized. Here we characterize I/SVOC emissions from aircraft, using a novel instrument for the online, quantitative measurement of the mass loading and composition of low-volatility organic vapors. Emissions from the NASA DC8 aircraft were sampled on the ground $143 \mathrm{~m}$ downwind of the engines and characterized as a function of engine power from idle ( $\sim 4 \%$ maximum rated thrust) through $85 \%$ power. Results show that I/SVOC emissions are highest during engine idle operating conditions, with decreasing but non-zero I/SVOC emissions at higher engine powers. Comparison of I/SVOC emissions with total hydrocarbon (THC) measurements, VOC measurements, and an established emissions profile indicates that I/SVOCs comprise $10-20 \%$ of the total organic gas-phase emissions at idle, and an increasing fraction of the total gas-phase organic emissions at higher powers. Positive matrix factorization of online mass spectra is used to identify three distinct types of I/SVOC emissions: aliphatic, aromatic and oxygenated. The volatility and chemical composition of the emissions suggest that unburned fuel is the dominant source of I/SVOCs at idle, while pyrolysis products make up an increasing fraction of the I/SVOCs at higher powers. Oxygenated I/SVOC emissions were detected at lower engine powers $(\leq 30 \%)$ and may be linked to cracked, partially oxidized or unburned fuel components.
\end{abstract}

\section{Introduction}

The climate (Unger, 2011), air quality (Hsu et al., 2012; Stettler et al., 2011; Unal et al., 2005) and health impacts (Arunachalam et al., 2011; Levy et al., 2011) of aircraft emissions have come under increasing scrutiny over the past decade. Aircraft emissions will likely play an increasingly important role in local and regional air quality due to continued growth in global commercial aviation (FAA, 2010) coupled with emission reductions in non-aviation transport sectors. Of particular importance to both the air quality and climate implications of aviation are organic species emitted from the evaporation, oxidation, and/or pyrolysis of fuels and lubricants. These emitted organic species include hazardous air pollutants (HAPs), serve as precursors to tropospheric ozone, and are key components of primary and secondary particulate matter (PM). A challenge in understanding these effects involves the high chemical complexity of organic compounds. Emitted non-methane hydrocarbons (NMHCs) include a very large number of organic species, whose amounts and properties are strongly dependent on engine power, fuel type, engine design, and environmental conditions (ambient temperature, background pollutant concentrations, etc.) (Knighton et al., 2007; Yelvington et al., 2007). Thus, to fully understand the air quality impacts of aviation emissions, it is necessary to obtain a comprehensive characterization of gas- and particle-phase organic emissions as a function of engine operating conditions.

Over the past decade, several studies have improved our understanding of aircraft emissions of particulate- and gasphase organic species. These include in-flight studies (Slemr 
et al., 2001, 1998) ground-based research programs (Wey et al., 2007), and plume studies at active airport terminals (Herndon et al., 2006, 2009). Measurements of volatile organic compounds (VOCs) and particulate matter, using both offline and online (real-time) techniques, have shown that VOC and PM emissions are highly dependent on engine power. Emissions of VOCs and non-refractory PM (sulfate and organics) are highest at engine idle and sharply decline with increasing engine power (Beyersdorf et al., 2012), whereas refractory PM (soot) emissions are greatest at high engine power (Onasch et al., 2009; Timko et al., 2010b; Williams et al., 2012). The chemical composition of the VOC emissions also changes with power, switching from predominately short-chain $\left(\mathrm{C}_{1-4}\right)$, unsaturated hydrocarbons and aldehydes at low power to longer-chain, higher-molecularweight aliphatic and aromatic hydrocarbon emissions at powers $\geq 15 \%$ (Anderson et al., 2006; Beyersdorf et al., 2012).

While most emissions characterization studies have focused on emissions of VOCs and PM, there is also strong evidence that aircraft emit lower-volatility gas-phase organic species that are not routinely measured using online analytical techniques (Presto et al., 2011; Robinson et al., 2010; Spicer et al., 1994, 1992). Such low-volatility species are classified as either (1) intermediate-volatility organic compounds (IVOCs), species with saturation vapor concentration $c^{*}$ of $10^{3}-10^{6} \mu \mathrm{g} \mathrm{m}{ }^{-3}$, present entirely in the gas phase, or (2) semi-volatile organic compounds (SVOCs), species with $c^{*}$ of $10^{-1}-10^{2} \mu \mathrm{g} \mathrm{m}^{-3}$, that partition between the gas and particle phases. These species are generally not measured in VOC characterization studies, due to their low volatilities (leading to enhanced losses on inlet surfaces) and/or their chemical complexity (so that the concentration of any one individual compound is below the detection limit for that compound).

Both IVOCs and SVOCs play important roles in PM emissions from aircraft. Primary organic aerosol (POA) is composed largely of SVOCs (Robinson et al., 2010), and the more volatile components of the POA will likely undergo substantial evaporation during dilution. Further, because of their low vapor pressures, I/SVOCs are likely to be efficient precursors to secondary organic aerosol (SOA) (Robinson et al., 2010, 2007), a key secondary pollutant arising from aircraft exhaust. Recent studies have shown that the oxidation of diluted aircraft exhaust leads to PM that is predominantly SOA, most of which appears to be produced from IVOCs and SVOCs (Miracolo et al., 2012, 2011). Because these compound classes likely make up a substantial fraction of the total organic emissions by aircraft, a predictive understanding of the air quality and climate implications of aviation requires their detailed measurement and characterization.

Measurements of low-volatility organic emissions from turbine engines are limited to a few studies, all of which have employed offline analysis techniques to characterize organics collected on sorbents or quartz filters (Agrawal et al., 2008; Presto et al., 2011, 2012; Spicer et al., 1992, 1994). This approach limits the temporal resolution of the measurements and requires steady-state engine operating conditions during sample collection. Nonetheless, results from these studies indicate that low-volatility organic emissions make up $\sim 20 \%$ of the total NMHC emissions at engine idle, with the vast majority ( $\sim 90 \%$ ) of compounds classified as unresolved complex matter (UCM), presumed to be a mix of branched and cyclic alkanes (Presto et al., 2011). Presto et al. (2011) showed that intermediate-volatility organic compounds (IVOCs) dominate the low-volatility organic emissions at $4 \%$ and $7 \%$ power, and attribute the IVOCs to unburned fuel. The prevalence of I/SVOC species in aircraft exhaust, the complexity of I/SVOC chemical composition, and the challenges associated with offline characterization techniques highlight the need for an ensemble-based, online characterization method that targets I/SVOCs.

The main goal of this investigation is to characterize I/SVOC emissions from aircraft exhaust, using a novel instrument for the online, quantitative measurement of the mass loading and composition of low-volatility organic vapors. A description of the instrument and overview of the sampling configuration used during the study are provided in the following section. Measurements of I/SVOC volatility, emission index and chemical characteristics taken during a power sweep of two engines on a chocked aircraft are then presented. I/SVOC emissions are examined as a function of engine power, with highest emissions of I/SVOC during engine idle operating conditions, and decreasing but nonzero I/SVOC emission at higher engine powers. Comparison of I/SVOC emissions with upstream total hydrocarbon (THC) measurements, VOC measurements, and an established emissions profile is used to assess the contribution of I/SVOCs to the total organic gas phase emissions from the engine. Differences in the magnitude, volatility, and chemical composition of the I/SVOC emissions are examined as a function of engine power. Results are used to identify potential sources of I/SVOC emissions during routine aircraft operation.

\section{Experimental}

\subsection{Measurement overview}

Measurements were made as part of the Alternative Aviation Fuels Experiment II (AAFEX-II), conducted from 26 March to 2 April 2011 at the Dryden Aircraft Operations Facility (DAOF) at Edwards Air Force Base in Palmdale, CA. Emissions from two high-bypass-ratio turbofan CFM56-2C1 engines on the NASA DC8 were characterized. During the testing, the DC8 was chocked on a concrete testing pad adjacent to a taxiway near the DAOF hanger. The inboard right engine (Engine \#3; E3) and inboard left engine (Engine \#2; E2) were operated from ground idle (4\% maximum rated thrust) through take-off powers $(100 \%$ thrust) with additional test points at $7 \%$ (taxi), $30 \%$ (approach), $65 \%$ (cruise), and $85 \%$ 
(climb out) power. With the exception of ground idle (4\%) and cruise $(65 \%)$, the power settings tested correspond to the International Civil Aviation Organization (ICAO) landing takeoff (LTO) cycle. The exact sequence and duration of the engine power sweeps did not follow the standard ICAO LTO cycle. In this experiment, each load was held for approximately $10-15 \mathrm{~min}$ with the exception of the $100 \%$ power condition, which was held for $2 \mathrm{~min}$. The duration of each test was determined by sampling considerations at the $1 \mathrm{~m}$ inlet which was translated across the exhaust plume over the course of each test point. In this study we focus on the morning of 30 March 2011. For these measurements, E2 burned Jet Propellant 8 (JP-8) fuel and E3 burned Sasol low-sulfur Fischer-Tropsch (FT) fuel. The aliphatic-to-aromatic content of the JP-8 fuel was $74.2: 25.8$ (wt. \%), whereas for the FT fuel the ratio was $99.5: 0.5$ (wt. \%). The olefin content of the FT fuel was twice as high as that of the JP- $8,1.4 \%$ versus $0.7 \%$ (E. Corporan, personal communication, 2012).

The I/SVOC measurements described here were made $143 \mathrm{~m}$ downwind of the aircraft, from inside of a sampling trailer positioned approximately $30 \mathrm{~m}$ from the centerline of the runway (on the E3 side of the DC8). This is sufficiently far away from the aircraft that the plumes from both E2 (JP8) and E3 (FT) were likely well-mixed. Thus, in the present study we generally cannot determine the detailed role of fuel type on I/SVOC emissions. However, as described in a later section, one plume hit at the end of the power ramp appears to be sampling E3 only, providing insight into how the use of FT fuel affects I/SVOC emissions. A more detailed investigation of the role of fuel type on low-volatility emissions, which requires a different experimental setup than was used here, is an important area of future research.

The custom inlet for I/SVOC measurements, shown in Fig. 1, consisted of a $3.5 \mathrm{~m}$ length of 1/4-inch o.d. stainless steel tubing, coated with SilcoNert 2000 (Silcotek, Inc.), and held at $250^{\circ} \mathrm{C}$ to reduce condensational losses. The sampling tip of the inlet was positioned $\sim 1 \mathrm{~m}$ above the roof of the trailer along the edge closest to the runway. Heat tape composed of fiberglass-insulated nichrome wire was used to maintain a uniform temperature $\left(250^{\circ} \mathrm{C}\right)$ for all inlet components, with an additional layer of fiberglass insulation wrapped around all inlet components to avoid cold spots. The inlet temperature was monitored with K-type thermocouples and set/maintained using commercial PID controllers (Omega Engineering). A SilcoNert-coated (SilcoTek, Inc.), heated metal filter was placed in line to prevent refractory soot particles from clogging the instrument inlet. At a temperature of $250^{\circ} \mathrm{C}$, the more volatile components of POA will evaporate, so that both particulate- and gasphase organic compounds are measured with the technique. The sampling flow rate through the I/SVOC inlet was held at $1.2 \mathrm{~L} \mathrm{~min}^{-1}$, using a small diaphragm pump (UN86KTP KNF Neuberger, Inc.). SilcoNert-coated, heated Swagelok tee connections at the inlet tip were configured to allow

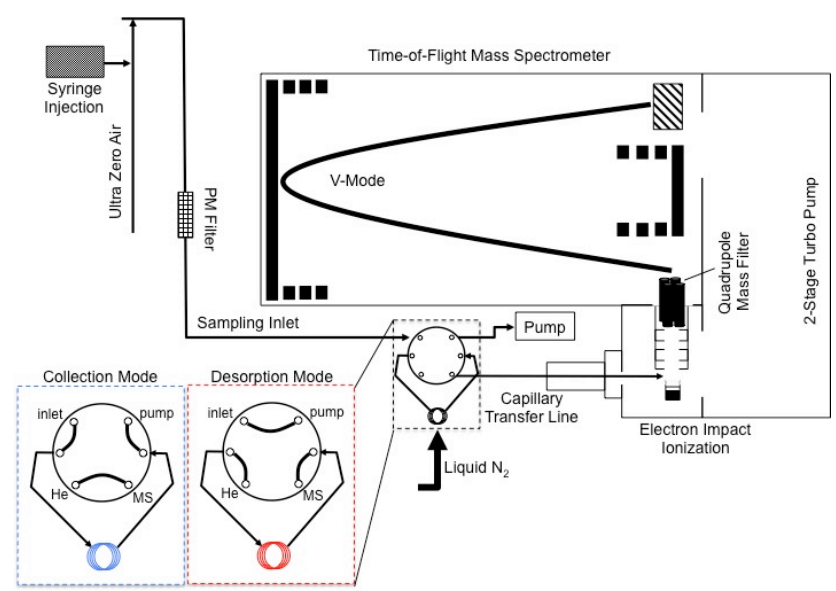

Fig. 1. Schematic of the I/SVOC instrument and inlet as configured during the AAFEX-II campaign. The inset shows the 6-way valve orientation for collection (blue) and desorption (red) modes of operation. See text for details.

blanks with ultra-zero air (UZA) and syringe calibration with known hydrocarbon standards throughout the experiment.

\subsubsection{I/SVOC measurement technique}

IVOCs and SVOCs were measured using a new instrument (Fig. 1), which involves the cryogenic collection (preconcentration) of organic species, followed by temperatureprogrammed desorption (TPD) into a stream of ultra high purity (UHP) helium, and finally detection and quantification by high-resolution electron impact mass spectrometry (EI-MS). This detection and quantification step is the same mass spectrometric approach used in the Aerodyne Aerosol Mass Spectrometer (AMS), an established technique for online, quantitative measurement of PM mass and chemical composition (Canagaratna et al., 2007; DeCarlo et al., 2006; Jayne et al., 2000). Thus the present instrument's acquisition and analysis of EI high-resolution mass spectra is similar to the AMS, but with a redesigned inlet system for the collection (rather than the exclusion) of gas-phase organic species. During sample collection, air is pulled at $0.4 \mathrm{~L} \mathrm{~min}^{-1}$ through the sample loop via a six-port valve (VICI Valco Instruments Co. Inc.) held at $250^{\circ} \mathrm{C}$. The valve and rotor are coated with Inertium coating AMC-18 (AMCX L.L.C.) to protect the heated, rotating components from excess wear. All other surfaces are coated with SilcoNert, in order to minimize interactions between the organics and metal surfaces. The collection loop itself is a 6-inch length of 1/16-inch o.d., 0.02-inch i.d., coated stainless steel tubing, wrapped tightly around a copper rod (1/2-inch diameter, 4-inch length) for rapid cooling and heating. Cryogenic cooling of the loop is achieved with a periodic spray of liquid nitrogen (LN2, from a $230 \mathrm{~L}, 22$ PSI Dewar) directed at the base of the copper rod, holding the temperature of the 
collection loop constant at $-6 \pm 2{ }^{\circ} \mathrm{C}$ during collection. After the collection period ( $2 \mathrm{~min}$ in the present study), the LN2 flow is stopped, the valve is rotated to the desorption configuration, and the collection loop is heated. In this mode, the UHP helium flow $\left(1 \mathrm{~cm}^{3} \mathrm{~min}^{-1}\right)$, which during collection is sent directly into the mass spectrometer, is now sent through the sample loop before entering the mass spectrometer, transferring desorbed organics directly into the ionization region. The desorption of the collected organics occurs according to the volatility of the species, resulting in the most volatile species desorbing at the lowest temperature, allowing for volatility-resolved measurements. The transfer line to the mass spectrometer is made of coated stainless steel ( $30 \mathrm{~cm}$ in length, $100 \mu \mathrm{m}$ i.d.) and is kept at $250^{\circ} \mathrm{C}$. Heating of the collection loop is achieved with a $100 \mathrm{~W}$ heater cartridge located in a bored hole in the center of the copper rod. The heating/cooling cycle is fully automated, using a computer-controlled PID that is programmable with respect to the collection temperature, collection time, desorption ramp rate and final desorption set and soak temperatures.

The mass spectrometer is an electron impact highresolution time-of-flight mass spectrometer (ToF-MS) equipped with a quadrupole mass filter (Tofwerk). The quadrupole mass filter was tuned to prevent helium ions from reaching the detector. For all measurements discussed here, the ToF-MS was in the "V" ion flight path mode, with a massresolving power of $\sim 2000$. Data acquisition and analysis programs developed for the AMS (http://cires.colorado.edu/ jimenezgroup/ToFAMSResources) are used to save and analyze the data.

During the AAFEX-II campaign, a collection/desorption cycle was completed every $\sim 9 \mathrm{~min}$, consisting of a $2 \mathrm{~min}$ collection at $-6 \pm 2{ }^{\circ} \mathrm{C}$, a 4 min linear ramp of temperature up to $280^{\circ} \mathrm{C}$, and a $1 \mathrm{~min}$ hold at $280^{\circ} \mathrm{C}$. On average it took $\sim 2$ min to cool the sample loop from $280^{\circ} \mathrm{C}$ back to the collection temperature set point, at which time the next collection cycle would begin. During each desorption cycle, mass spectra were saved at a rate of $2 \mathrm{~Hz}$, allowing for the straightforward alignment of mass spectra and desorption temperatures (which were measured at $1 \mathrm{~Hz}$ ) and enabling presentation of data as thermograms (ion intensities as a function of desorption temperature).

Instrument response was calibrated with syringe injections (10-600 $\mathrm{nL} \mathrm{min}^{-1}, 250 \mu \mathrm{L}$ syringe, Harvard Apparatus Syringe Pump) of a $\mathrm{C}_{8}-\mathrm{C}_{20}$ straight-chain $n$-alkane standard (40 $\mathrm{mg} \mathrm{mL}^{-1}$ of each alkane in hexane solvent; SigmaAldrich Co. LLC) connected via a tee-junction at the sampling inlet tip (see Fig. 1). Calibrants were introduced into the instrument using an overflow of heated ultra-zero air (UZA; AirGas, Inc.). The air was sent past the syringe tip in slight excess $\left(+0.3 \mathrm{~L} \mathrm{~min}^{-1}\right)$ of the demand flow of the downstream instrumentation, with the majority of the flow entering the inlet (and the excess flow escaping to the air surrounding the sampling inlet tip). This configuration ensures that the calibrant organic species are measured only after pass- ing through the entire inlet length, thereby including any potential wall effects in the quantification of the IVOC/SVOC measurement. Mass loading calibration data points are obtained by varying the injection rate $\left(10-600 \mathrm{~nL} \mathrm{~min}^{-1}\right)$ of the calibration standard and relating the known mass concentration $\left(\mu \mathrm{g} \mathrm{m}^{-3}\right)$ of organics to the total high-resolution organic ion signal intensity. This is determined by fitting and summing all ions $(m / z \leq 120)$ associated with organic species in each mass spectrum (DeCarlo et al., 2006), with the exception of ions with exceedingly high background levels $\left(\mathrm{H}_{2} \mathrm{O}^{+}, \mathrm{CO}_{2}^{+}\right)$. Within each desorption, the total organic signal was summed between $50^{\circ} \mathrm{C}$ and $280^{\circ} \mathrm{C}$ (see for example the lower panel of Fig. 2). Summing the organics within this temperature region allows unambiguous separation of any collected solvent (hexane, which desorbs at temperatures $<50^{\circ} \mathrm{C}$ ) and the larger $n$-alkane calibration species.

In addition to the mass calibration, an empirical relationship between the observed peak desorption temperature and volatility can also be determined from the known vapor pressures of the individual hydrocarbons in the calibration standard. The upper panel of Fig. 2 shows the clear relation between saturation vapor concentration $\left(c^{*}\right)$ and peak desorption temperature for a laboratory calibration prior to the AAFEX-II deployment. Unfortunately, because of changes to the sampling line and an apparent loading dependence of the $c^{*}-T$ relationship, we were unable to obtain a robust volatility calibration during AAFEX-II. Therefore we do not assign precise values of $c^{*}$ to specific temperatures, and instead define the general volatility bounds of the IVOC and SVOC species, as illustrated at the top of Fig. 2 based on previous laboratory calibrations.

These approximate volatility ranges are strongly supported by the desorption profiles of pure FT and JP-8 fuels, shown in Fig. 3. These measurements were taken in the laboratory following the AAFEX-II campaign from aliquots of fuel identical to those used in the field experiment. For each collection the neat fuel of interest was continuously injected $\left(25 \mathrm{nl} \mathrm{min}^{-1}\right)$ into a flow of $2.0 \mathrm{Lpm}$ of UZA. Each sample collection lasted $60 \mathrm{~s}$ with the sample loop held at $-6 \pm 2{ }^{\circ} \mathrm{C}$. For these experiments, a shortened inlet system was used relative to the field-deployed AAFEX-II inlet, so the correspondence of neat-fuel and exhaust-plume volatility distributions may not be perfect. The fuel data, however, still provides an approximate relationship between the known volatility and observed desorption temperatures for unburned fuel. These fuels fall squarely in the IVOC range, as expected for hydrocarbon species with $12-16$ carbon atoms. Additionally, we note that the measured chemical composition of the species identified as "fuel" in the mass spectrum is broadly consistent with the known chemical makeup of the fuel, with desorption profiles of marker ions for aliphatic $\left(\mathrm{C}_{6} \mathrm{H}_{13}^{+}, m / z\right.$ 85.102) and aromatic $\left(\mathrm{C}_{9} \mathrm{H}_{7}^{+}, m / z\right.$ 115.055) compounds, showing a far lower aromatic content for FT than JP-8. 


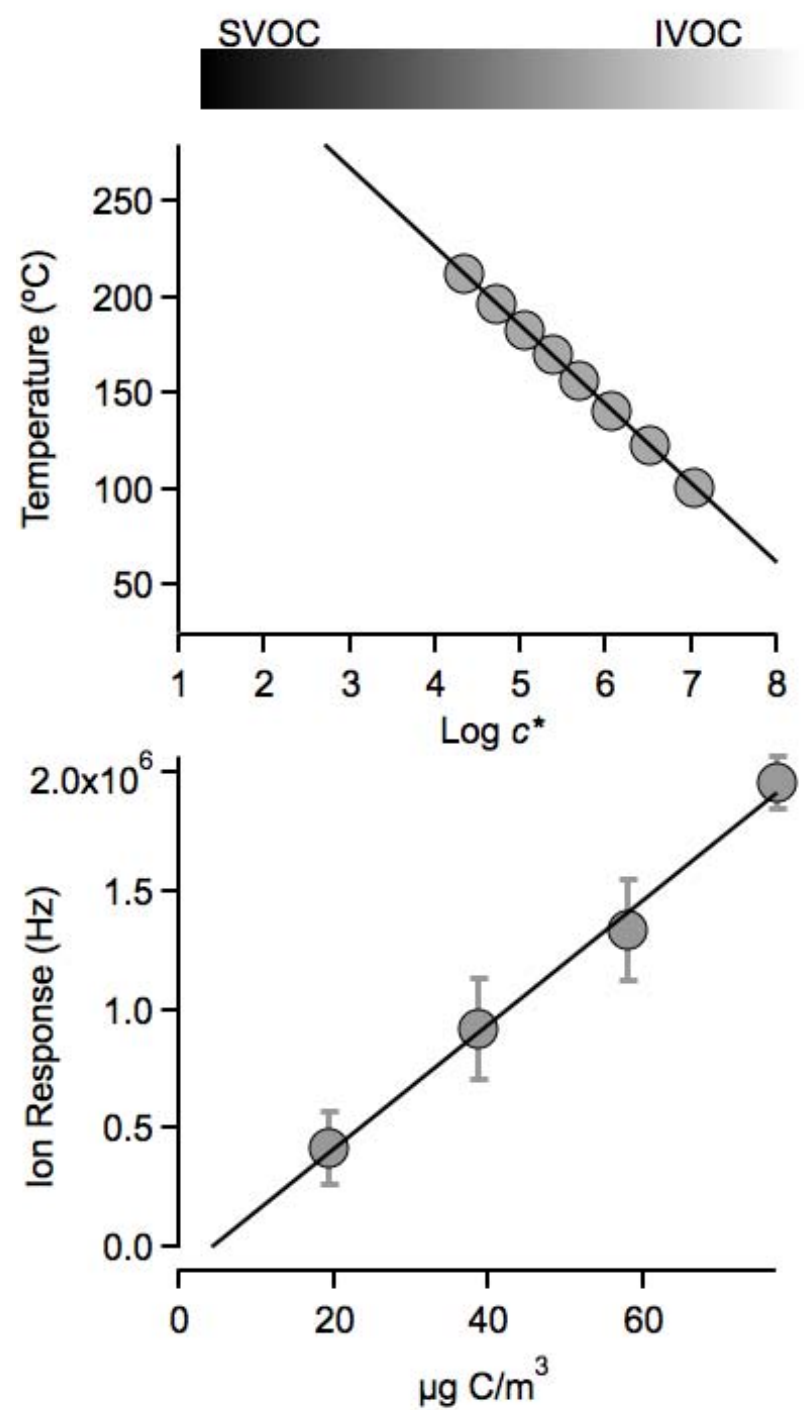

Fig. 2. Laboratory calibration results for the I/SVOC instrument, using syringe injections of known straight-chain $n$-alkanes. Top panel: empirical relationship between desorption temperature and saturation vapor concentrations of $\mathrm{C}_{13}-\mathrm{C}_{20}$ alkanes. A robust fieldbased calibration for the $c^{*}-T$ relationship was not obtained during AAFEX-II. Therefore, we define the general volatility bounds of the IVOC and SVOC species with the grey-scale bar shown along the top of the figure. Bottom panel: total mass spectrometric signal for different mass concentrations of injected straight-chain $\mathrm{C}_{8}-\mathrm{C}_{20}$ $n$-alkane standard, demonstrating the linearity and sensitivity of the instrument.

During AAFEX II, blanks with UZA were performed regularly to confirm that the inlet walls do not act as a source of low-volatility organics. For the measurements discussed here, UZA blanks were collected at the beginning and end of the engine power ramp and used as background subtractions for the jet exhaust desorption profiles. In all cases, the total organic signal measured during UZA runs was very low (less than $1 \%$ of the total organic signal measured under en-

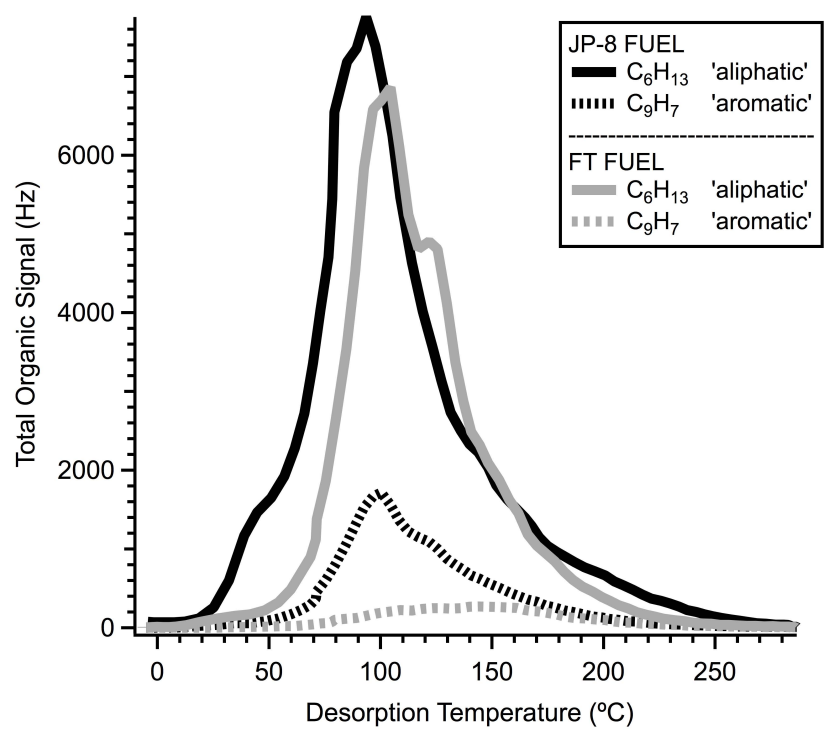

Fig. 3. Desorption profiles for representative aliphatic $\left(\mathrm{C}_{6} \mathrm{H}_{13}^{+}\right)$and aromatic $\left(\mathrm{C}_{9} \mathrm{H}_{7}^{+}\right)$ion fragments obtained from neat fuel injections of JP-8 and FT. As expected based on their chemical compositions, aliphatic signal is high for both fuels, whereas aromatic signal is significant only for JP-8.

gine idle operating conditions), confirming that inlet surfaces did not serve as a significant source of organic contamination during the experiment. Ambient background pollutant concentrations varied throughout the experiments and were typically highest during the early morning periods, due to increased fuel truck activity in the immediate vicinity of the DC8 prior to starting the aircraft engines. Following startup, the wind field produced by the aircraft engines provided sufficient flow to purge the diesel truck emissions from the sampling area.

\subsection{Other AAFEX II measurements}

Other instrumentation in the $143 \mathrm{~m}$ trailer included a nondispersive infrared absorption $\mathrm{CO}_{2}$ monitor (LI-COR Biosciences LI-840A), to identify plume hits and quantify plume dilution, and a custom-built weather station for monitoring ambient temperature, relative humidity, dew point, barometric pressure, wind speed, wind direction and solar flux. The weather station was mounted on the roof of the $143 \mathrm{~m}$ trailer $\sim 1 \mathrm{~m}$ above the sampling height of the I/SVOC inlet. In addition to the stationary platforms, the Aerodyne Mobile Laboratory (Kolb et al., 2004) was used throughout the experiment to intercept and sample the exhaust plume over a range of spatial/temporal scales, to better interrogate the downwind processing of the aircraft emissions. Instruments inside the mobile lab relevant to the current study included a Quantum Cascade Tunable Infrared Laser Differential Absorption Spectrometer (QC-TILDAS), Proton Transfer Reaction Mass Spectrometer (PTR-MS) and non-dispersive infrared 


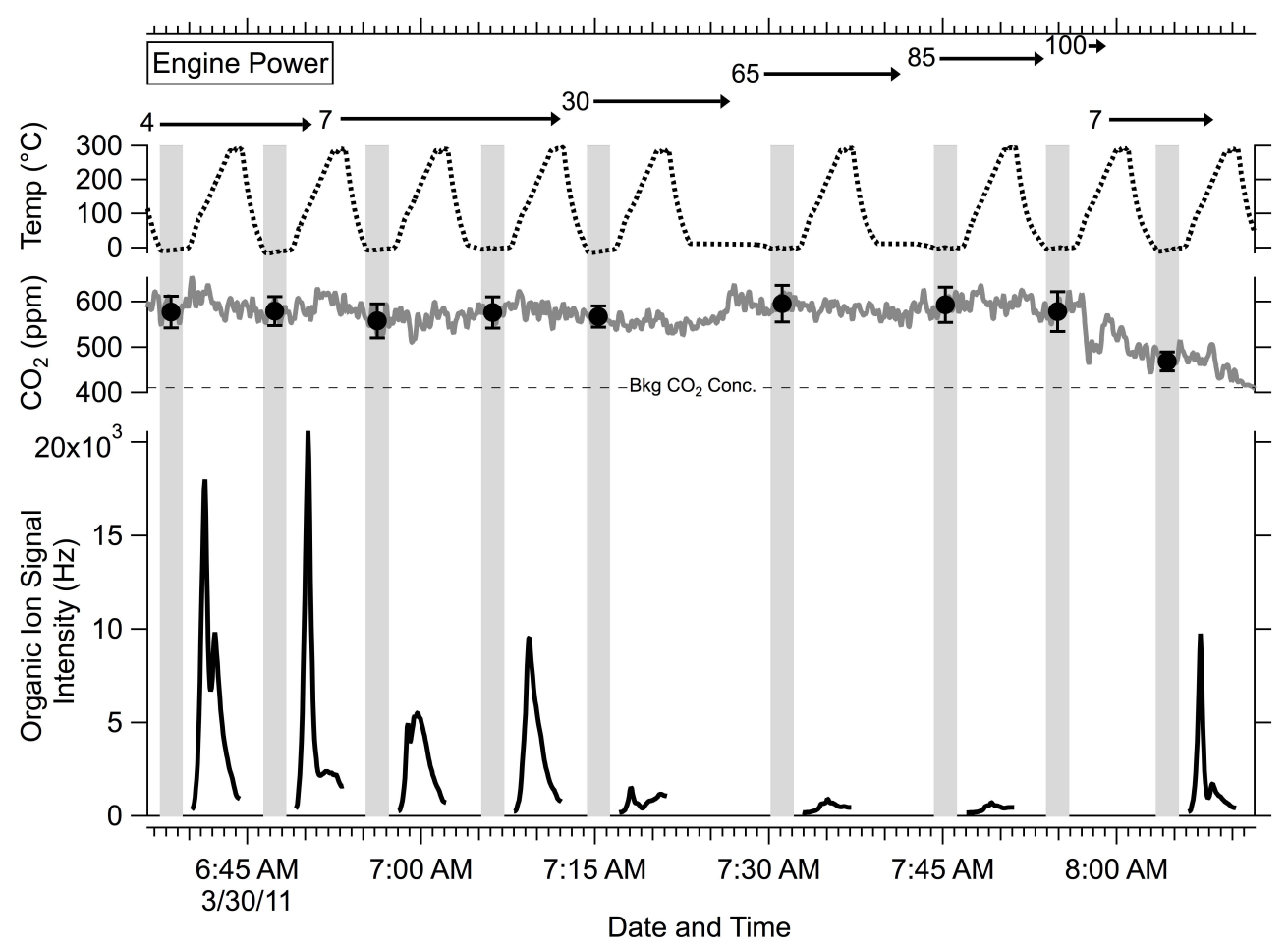

Fig. 4. Timeline showing the sample collection/desorption cycles during the 30 March 2011 power sweep: jet engine power setting, measured $\mathrm{CO}_{2}$ level at $143 \mathrm{~m}$, collection temperature, collection period and total organic ion signal. Elevated $\mathrm{CO}_{2}$ levels recorded at the $143 \mathrm{~m}$ inlet position are shown in the middle panel, with the dashed line demarcating the ambient $\mathrm{CO}_{2}$ background concentration.

$\mathrm{CO}_{2}$ detector. To assess the relative contributions of VOC and I/SVOC emissions to the total organic emission profile from the engine, THC measurements from a flame ionization detector (FID) are also utilized, which made measurements $1 \mathrm{~m}$ behind the engine exit plane. Results from these comparisons are presented in the following section.

\section{Results and discussion}

\subsection{Overview of sampled plumes}

Given the distance between the aircraft and the $143 \mathrm{~m}$ sampling inlet, the semi-continuous nature of the collection cycles, variability in ambient wind speed and direction, and the limited time assigned to each specific engine operating condition, not all collection cycles coincided with definitive aircraft exhaust plume hits at $143 \mathrm{~m}$. Figure 4 provides a summary of the $143 \mathrm{~m}$ data collected over the course of the early morning power sweep on 30 March 2011. Exhaust plume hits are characterized by elevated $\mathrm{CO}_{2}$ concentrations ( $\triangle \mathrm{CO}_{2} \sim 70-200 \mathrm{ppm}$ relative to ambient background), as shown in the middle panel of Fig. 4. Engine powers are designated along the top of the figure along with the temperature cycle (dashed line) of the collection/desorption cell (collection: $-6^{\circ} \mathrm{C}$; desorption ramp: $\sim 280^{\circ} \mathrm{C}$ ). The grey shaded bars in the figure designate the time period during which the low-volatility organic vapors were collected.

For the series of power conditions tested, the $\Delta \mathrm{CO}_{2}$ values at $143 \mathrm{~m}$ do not systematically increase with increasing engine power, likely due to the different entrainment and dilution with ambient air at different engine powers. The distance between the sampling inlet and the aircraft engines also introduces more run-to-run variability for a given engine power condition as compared with emissions data captured from upstream $(1 \mathrm{~m}, 10 \mathrm{~m})$ inlet positions. As mentioned earlier, it is generally assumed that emissions from both E2 and E3 were mixed prior to reaching the $143 \mathrm{~m}$ position. This appears to be the case for the upward power ramp on 30 March, but the transition from $100 \%$ power to $7 \%$ power at the end of the test cycle coincided with a shift in the wind direction. Considering the orientation of the aircraft with respect to the $143 \mathrm{~m}$ sampling inlet, it is likely that the last $7 \%$ collection exclusively measured the emissions from E2 (burning the alternative Sasol low-sulfur FT fuel). This is further supported by the observed drop in $\Delta \mathrm{CO}_{2}$ by factor of $\sim 2$ relative to earlier $7 \%$ collections. For this reason, the final $7 \%$ power condition will be discussed separately from the mixed-plume data. In addition, two of the collection periods overlapped at least partially with a transition in engine power (from $7 \%$ to $30 \%$ and from $65 \%$ to $85 \%$ ). It is likely 


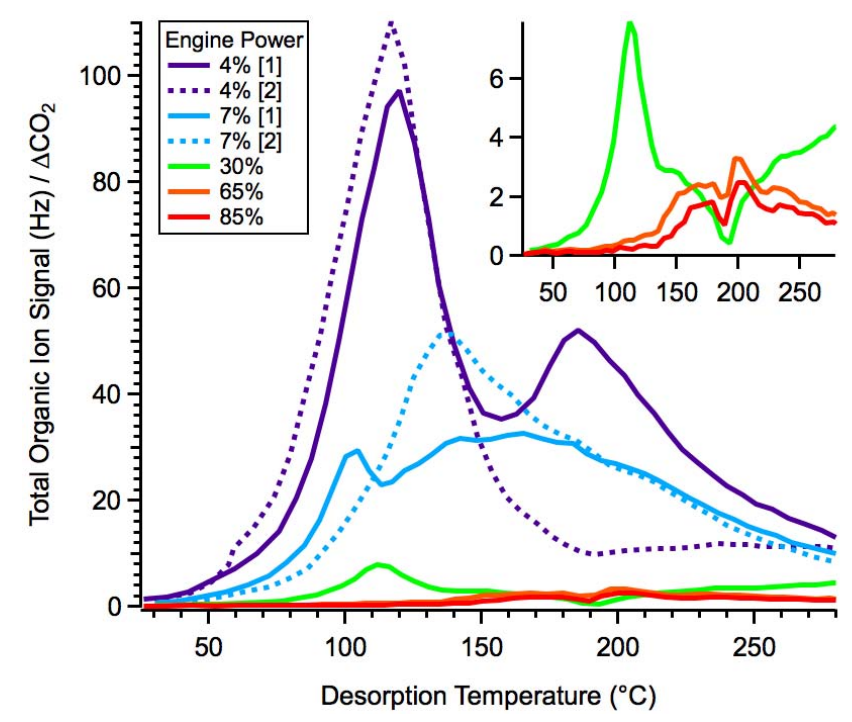

Fig. 5. Desorption profiles of total organic signal, divided by $\mathrm{CO}_{2}$ enhancement to account for dilution, for each engine power condition. Inset shows the desorption profiles for engine powers $\geq 30 \%$.

that during these collections, both transient and steady-state I/SVOC emissions were captured.

\subsection{Dependence of loading and volatility on engine power}

Total I/SVOC emissions were measured by the total organic mass spectrometric signal, integrated over the desorption. As with the calibration experiments, total organic signal was defined as the sum of all high-resolution organic ions, with the exception of $\mathrm{H}_{2} \mathrm{O}^{+}$and $\mathrm{CO}_{2}^{+}$due to their high backgrounds. In this experiment, approximately $90 \%$ of the organic ion signal is found at $m / z \leq 100$. Absolute organic signal intensities for each desorption during the power ramp are shown in the bottom panel of Fig. 4.

Trends in both the amount and volatility of I/SVOC organic emissions as a function of engine power are examined more closely in Fig. 5. To compare emissions from different collections, the total organic ion intensity is normalized to average $\Delta \mathrm{CO}_{2}$ measured during each collection interval, yielding an emission ratio. Changes in both the amount and volatility of the emissions are strongly dependent on engine power. Emissions are highest at $4 \%$ power (idle), and decrease substantially at higher powers, with a particularly large decrease between $7 \%$ and $30 \%$ (inset of Fig. 5). The volatility distribution of the organics is also power-dependent, with the lowest-volatility organics tending to dominate at the highest powers. Organics emitted at $4 \%$ power (idle) desorb at relatively low temperatures (corresponding to higher-volatility species); the major desorption peak at $\sim 120^{\circ} \mathrm{C}$ corresponds reasonably well to that of pure fuel (Fig. 3), suggesting that the IVOCs measured in the jet plume correspond to unburned fuel emitted from the aircraft engine at idle. The correspondence is not exact, possibly because of differences between the inlet systems, but the general correspondence is consistent with previous investigations of unburned fuel emissions.

A second, higher-temperature mode is observed for the first $4 \%$ power collection but not for the second $4 \%$ power collection. The source of this difference is not clear, and may be related to variability in engine emissions and/or environmental factors such as shifts in the transport of the exhaust plume to the $143 \mathrm{~m}$ sampling location. At slightly higher engine power $(7 \%)$, the desorption profiles are broader and shifted to slightly higher temperatures (lower volatilities). These may include some contribution from unburned fuel (mode below $150^{\circ} \mathrm{C}$ ), but also suggest contributions from other combustion processes such as pyrolysis. At $30 \%$ engine power, a minor high-volatility mode corresponding to unburned fuel is still detected, though this may well be a transient from the recent power increase from $7 \%$. There is an increasing contribution from lower-volatility organics at $30 \%$ power, potentially resulting from the formation of pyrolysis products from the higher temperatures and pressures of this engine operating state. At the highest powers studied, organic signal is observed only at the highest desorption temperatures (lowest volatilities), indicating no measurable emissions of unburned fuel but rather newly formed low-volatility organics.

\subsection{Contribution of I/SVOCs to total aircraft emissions}

By summing total organic signal over a full desorption cycle and applying the measured calibration factor, we can estimate total I/SVOC concentrations for each captured jet exhaust plume intercepted at $143 \mathrm{~m}$. An emission index (EI, in $\mathrm{mg}$ of emitted organic material per $\mathrm{kg}$ fuel combusted) can then be determined, via

$\mathrm{EI}=\frac{\Delta M}{\Delta \mathrm{CO}_{2}} \frac{T}{P} \times 4478$,

where $\triangle M$ is the measured $\mathrm{I} / \mathrm{SVOC}$ mass concentration in $\mu \mathrm{g} \mathrm{m}^{-3}, \Delta \mathrm{CO}_{2}$ is the difference between the sample and ambient $\mathrm{CO}_{2}$ concentrations (in ppmv), $T$ is the sampling temperature in Kelvin, and $P$ is the ambient pressure in Torr. The constant (4478) incorporates an emission index for $\mathrm{CO}_{2}$ of $3160 \mathrm{~g} \mathrm{CO}_{2} \mathrm{~kg}^{-1}$ fuel, which assumes $100 \%$ combustion efficiency and a fuel hydrogen-to-carbon ratio of 1.9. This approach is consistent with the methodology used in the E31 EI calculator (Herndon et al., 2006; Timko et al., 2010a).

Figure 6 displays I/SVOC emission indices as a function of engine power (grey circles), and shows the dramatic decrease in emissions with increasing power. Also shown are THC emissions as a function of power, determined from flame ionization detection (FID) at the $1 \mathrm{~m}$ inlet position for E2 (burning FT) and E3 (burning JP-8) (data courtesy of Changlie Wey, NASA). In addition, total organic emissions 


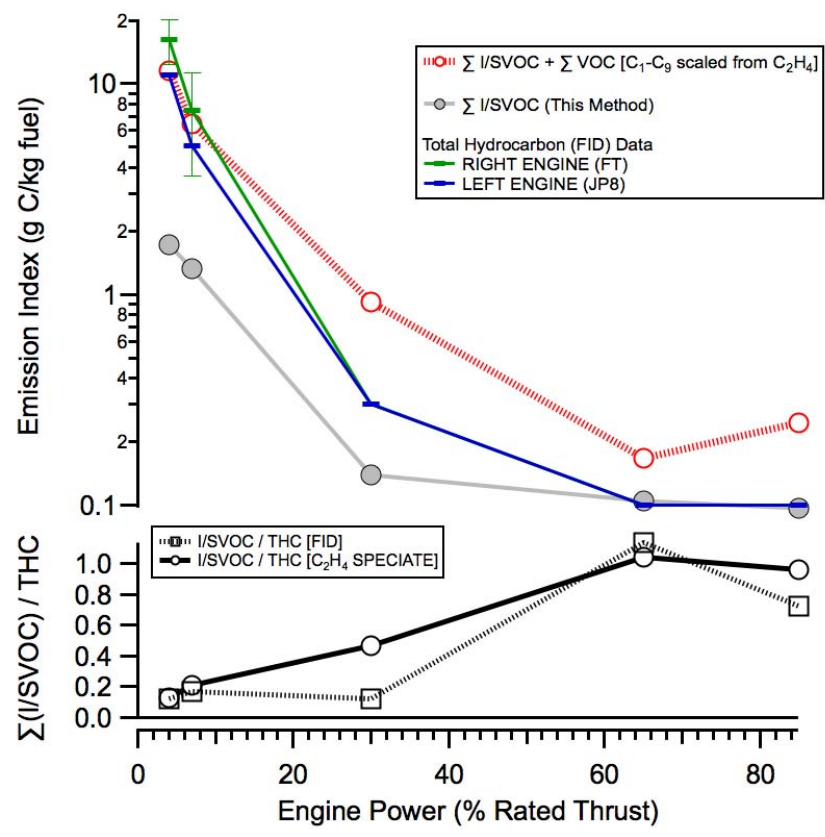

Fig. 6. Emissions of I/SVOCs as a function of engine power. Upper panel: power-dependent emission indices of I/SVOCs (measured with the present method), THC (measured with FID at $1 \mathrm{~m}$ ) for each engine, and the sum of total VOCs (as estimated from measurements of $\mathrm{C}_{2} \mathrm{H}_{4}$ using the SPECIATE inventory) and I/SVOCs as a function of engine power. Lower panel: power-dependent ratios of measured I/SVOCs to total organic emissions. Two ratios are displayed, one based on the measured THC values and a second estimate from the scaled $\mathrm{C}_{2} \mathrm{H}_{4}$ measurements.

are estimated from known emission profiles. Total VOC emissions $\left(\mathrm{C}_{1}-\mathrm{C}_{9}\right.$ hydrocarbons) are estimated by scaling up measurements of ethene (obtained using the QC-TILDAS instrument in the Aerodyne mobile lab, which was adjacent to the $143 \mathrm{~m}$ inlet during these tests) using the SPECIATE organic gas emission profile for aircraft (SPECIATE database profile \#5565). To ensure that the scaled VOC and measured IVOC quantities did not overlap (and therefore to avoid double-counting), all hydrocarbon species $\geq \mathrm{C}_{10}$ in the SPECIATE profile were excluded from the scaled VOC quantity. The sum of scaled VOC and measured I/SVOC measurements is then compared to the average THC measurements for E2 and E3. At low powers the two techniques generally agree, though at higher powers the scaled VOC $+\mathrm{I} / \mathrm{SVOC}$ total is consistently higher than the THC measurement. This may arise from the fact that oxygenated organics are not measured efficiently with FID (no corrections for oxygenates are applied to the FID measurements). Oxygenated HCs measured by the I/SVOC instrument at $30 \%$ power may explain part of the enhancement observed in Fig. 6. Also, all THC values were obtained at steady-state conditions, and it is possible that the I/SVOC measurement at $30 \%$ power was influenced by transient emissions (changing from 7 to $30 \%$ power). Finally, the loss of lower-volatility organic species to inlet surfaces may contribute to lower THC values measured with the FID.

The bottom panel of Fig. 6 shows the ratio of I/SVOC emissions to the average measured THC emissions. At low engine power the I/SVOC emissions make up 10-20\% of the total hydrocarbon emissions. This is qualitatively similar to the results of Presto et al. (2011), which indicated that $\sim 20 \%$ of the NMHC emissions at idle engine power were IVOCs. In addition, we find that as the engine power increases, the I/SVOC fraction also increases, reaching $100 \%$ of the THC emissions at $65 \%$ and $85 \%$ power. Care must be taken to not over-interpret these results given uncertainties in the FID THC detection limit and the low overall organic emissions at high power. Nonetheless, nonzero I/SVOC emissions at these operating conditions suggest that pyrolysis-derived low-volatility organic compound emissions remain present in the exhaust plume at high power.

Evaporated POA may also serve as a source of the lowvolatility organics measured at high engine powers. A significant fraction $(5-100 \%)$ of aircraft engine POA is attributed to lubricating oil emissions (Yu et al., 2012), but the thermal and chemical stability of the lubricants suggest that these species will remain in the condensed phase even within the heated inlet of the I/SVOC instrument. Lubricantderived POA would therefore remain trapped in the PM filter of the I/SVOC inlet system and not reach our collector. Further, analysis of the I/SVOC mass spectra collected here do not show enhancement in the ratio of $\mathrm{m} / \mathrm{z} 85$ to $\mathrm{m} / \mathrm{z}$ 71 , which has been observed as a characteristic feature of electron-impact mass spectra of lubricant-derived POA (Yu et al., 2010, 2102).

\subsection{Chemical features of emitted I/SVOCs: $7 \%$ plume}

While the thermograms in Fig. 5 provide information about the amount and volatility of the emitted IVOCs and SVOCs, they offer little insight into the chemical nature and sources of these lower-volatility organics. However, a strength of the mass spectrometric approach used here is that it also provides chemical information about the sampled organic species, which can be used to better constrain the properties and origins of engine emissions. Electron impact ionization results in fragmentation of parent molecules, generating characteristic ions for different classes of organics such as aliphatic, aromatic or oxygenated hydrocarbons. As an example, Fig. 7 shows thermograms for several marker ions at one of the $7 \%$ power conditions. Different ions exhibit distinct desorption profiles, with desorption maxima at different temperatures; this is in strong contrast to the total organic desorption profile (also shown), which consists of a broad volatility distribution that lacks defined peaks. This single desorption mode is thus a combination of a number of different classes of organics, spanning a range of composition, properties, and sources.

The $\mathrm{C}_{6} \mathrm{H}_{13}^{+}$ion $(\mathrm{m} / z$ 85.102) is representative of aliphatic hydrocarbons, and the desorption profile (with a peak at 


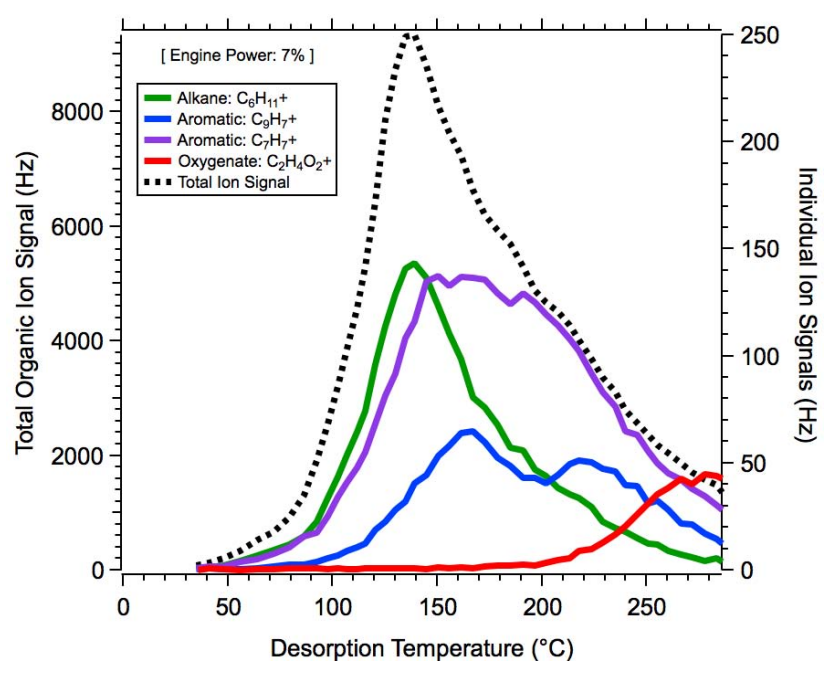

Fig. 7. Selected desorption profiles at $7 \%$ engine power. Right axis: total organic ion signal. Left axis: key marker ions of aliphatic $\left(\mathrm{C}_{6} \mathrm{H}_{13}^{+}\right)$, aromatic $\left(\mathrm{C}_{9} \mathrm{H}_{7}^{+}, \mathrm{C}_{7} \mathrm{H}_{7}^{+}\right)$, and oxygenated $\left(\mathrm{C}_{2} \mathrm{H}_{4} \mathrm{O}_{2}^{+}\right)$organic species.

$140^{\circ} \mathrm{C}$ ) indicates the parent alkanes are relatively volatile. Both the chemical signature and volatility are consistent with unburned fuel (Fig. 3). The total organic ion signal peaks at a similar temperature, suggesting that unburned fuel makes up a substantial portion of the total IVOC emissions at this power. However, the importance of other types of ions, mostly at higher desorption temperatures, strongly suggest additional sources of I/SVOCs as well. The $\mathrm{C}_{8} \mathrm{H}_{7}^{+}$ and $\mathrm{C}_{7} \mathrm{H}_{7}^{+}$ions, associated with aromatic hydrocarbons, appear at somewhat higher temperatures, with a multi-modal volatility distribution. A portion of these emissions may be from unburned fuel, since the aromatic content of JP-8 fuel is high (see Fig. 3). Additionally, aromatics can be formed from pyrolysis within the combustor burning either JP-8 or FT fuel. The widths of the volatility distributions for the aromatic ion fragments suggest that both sources (unburned fuel and pyrolysis) may be important at $7 \%$ power. Further, the higher desorption temperatures suggest that aromatic pyrolysis products may be lower in volatility (higher in molecular weight) than the aromatics in unburned fuel. The final ion fragment shown in Fig. 7 is $\mathrm{C}_{2} \mathrm{H}_{4} \mathrm{O}_{2}^{+}$, an oxygenated organic ion. This ion is present at lower concentrations than the aliphatic and aromatic fragment ions and occupies the lowest volatility range of organics measured for this particular $7 \%$ power condition. The source of this class of compound is unclear, though it may be related to the partial oxidation of fuel within the combustor. It is important to note that using single ions as proxies for entire compound classes has inherent limitations. For a more complete chemical characterization, the full mass spectral profiles and multiple power conditions must be examined as described in the following section.

\subsection{Chemical features of emitted I/SVOCs: all engine powers}

The examination of key marker ions as a function of desorption temperature (Fig. 7) yields insight into the nature and sources of different organic types. However, that approach relies on a small fraction of the chemical information available with the instrument described here. Each desorption shown along the bottom panel of Fig. 4 is comprised of more than 1000 high-resolution mass spectra, each with $>250$ identified ions. In order to better characterize the chemical makeup of the different classes/sources of I/SVOC emissions, we use positive matrix factorization (PMF), a factor analysis technique (Paatero and Tapper, 1994) that has seen widespread use in identifying components of organic aerosol from AMS data (Lanz et al., 2007; Ulbrich et al., 2009; Zhang et al., 2011). The PMF analysis of timedependent (temperature-dependent) mass spectra allow for engine I/SVOC emissions to be described in the same way, in terms of key classes of organics, with characteristic mass spectra and dependences on volatility and engine power.

Results from the PMF analysis are summarized in Fig. 8a and $b$ (a more detailed description of the PMF analysis procedures is provided in the supplemental material). After evaluation of mass spectral profiles and time (temperature) traces, a four-factor PMF solution was chosen (FPEAK $=0$; $\mathrm{Q} / \mathrm{Qexp}=0.06)$ to describe the variability of the data. Amongst the four-factor solution, one factor was invariant with changing engine power and had common spectral ion signatures as the UZA blank, including siloxane fragment ions. Based on this evidence, this factor was assigned as background and is not included in the analysis of the aircraft engine I/SVOC emissions. The remaining three factors reveal distinct I/SVOC signatures that can be attributed to three general chemical classes, aliphatic, aromatic, and oxygenated organics. The power-specific desorption profiles of these three factors are shown in Fig. 8a. The corresponding mass spectra for each factor are shown in Fig. 8b. Estimates of $\mathrm{H}: \mathrm{C}$ and $\mathrm{O}: \mathrm{C}$ ratios (displayed in Fig. 8b) are obtained from the high-resolution mass spectra using the approach of Aiken et al. (2007, 2008), though without any empirical correction accounting for effects of EI fragmentation. Such approximations may influence the absolute elemental ratios, but the qualitative differences in $\mathrm{H}: \mathrm{C}$ and $\mathrm{O}: \mathrm{C}$ among the different PMF factors will not be affected.

The I/SVOC volatility distributions shown in Figure $8 \mathrm{a}$ summarize the variability in aliphatic, aromatic, and oxygenated I/SVOC emissions with increasing engine power. In the upper panel of Fig. 8b, the aliphatic factor mass spectrum has major ion fragments at $\mathrm{m} / \mathrm{z}, 41.039,43.055$, $55.055,57.070,69.070,71.086,83.086$, and 85.102 showing the characteristic "picket fence" $(\Delta m / z=14)$ fragmentation pattern indicative of alkanes. High-resolution analysis reveals that the aliphatic factor has low oxygen content $(\mathrm{O}: \mathrm{C}=0.03)$ and high hydrogen content $(\mathrm{H}: \mathrm{C}=2.07)$, 


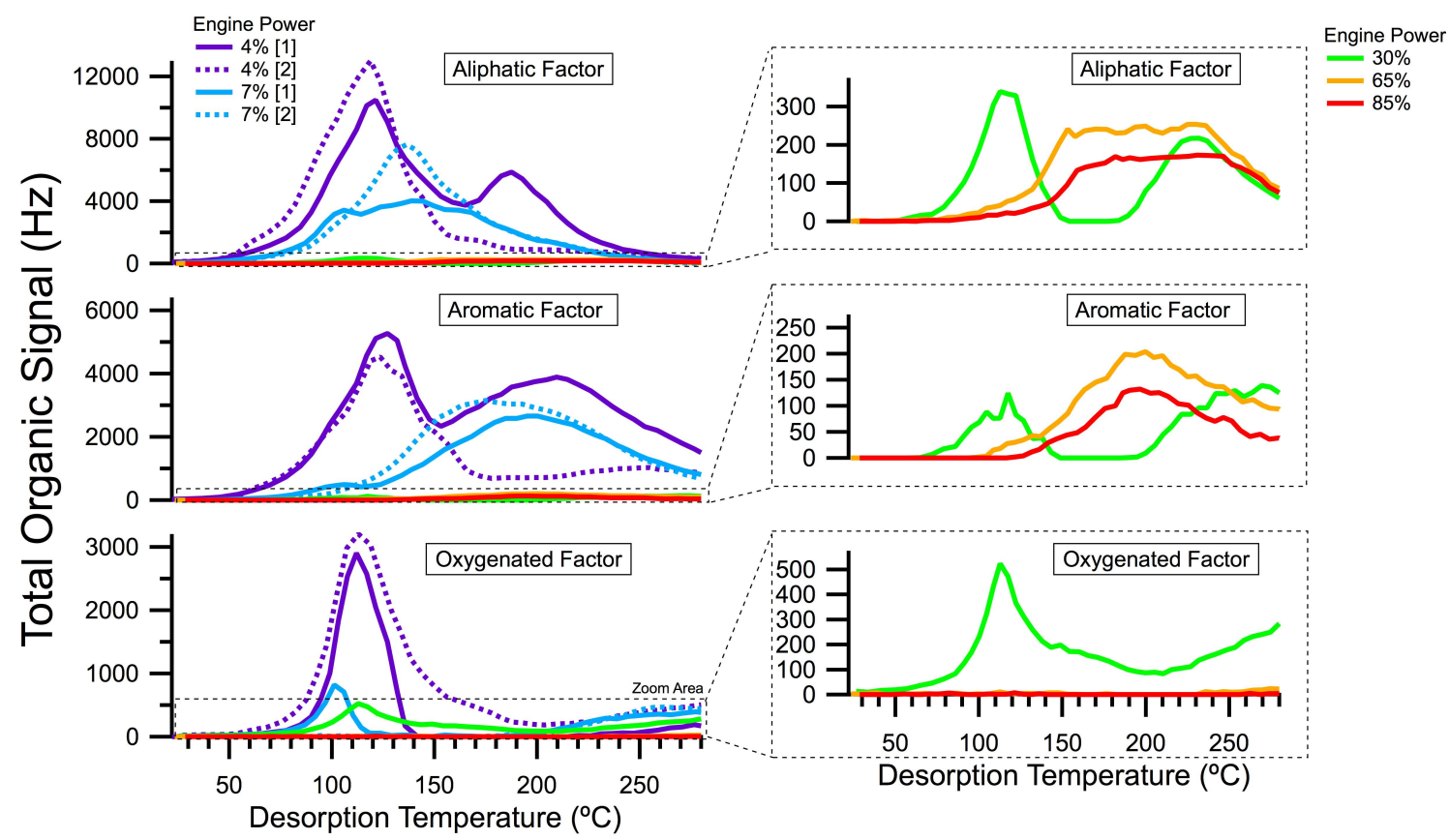

Fig. 8a. Desorption profiles for aliphatic, aromatic, and oxygenated PMF factors. Results obtained from higher engine powers ( $\geq 30 \%)$ are re-scaled on the right-hand side of the graph for clarity.

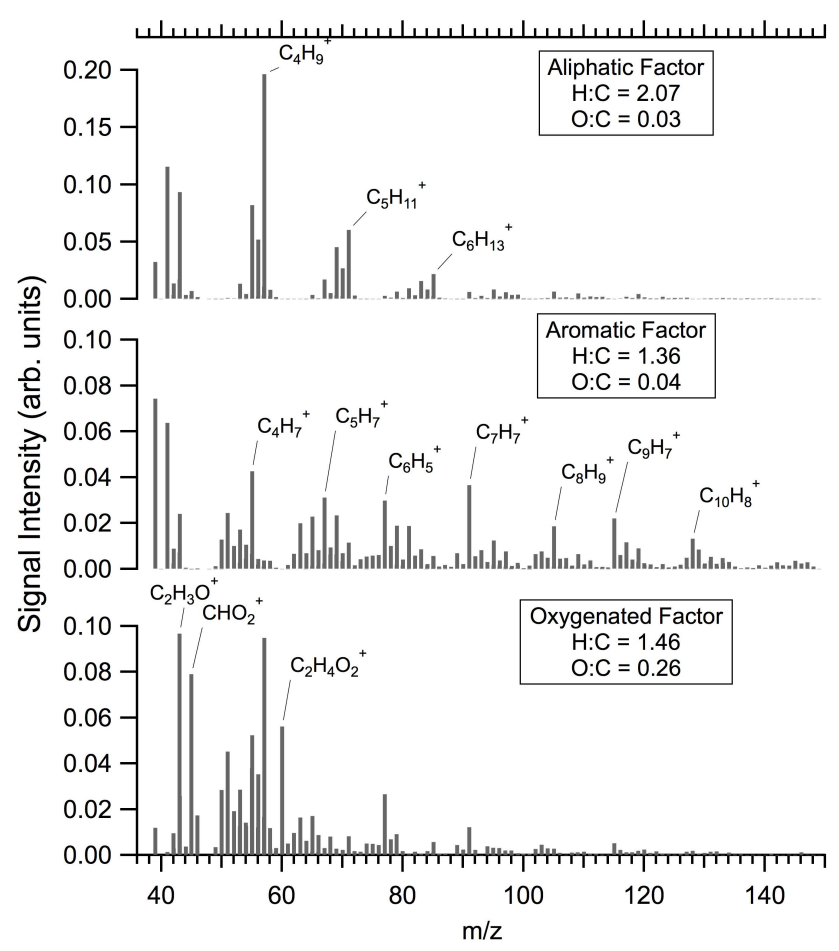

Fig. 8b. Aliphatic, aromatic, and oxygenated PMF factor mass spectra and $\mathrm{O}: \mathrm{C}$ and $\mathrm{H}: \mathrm{C}$ ratios for each. consistent with the saturated aliphatic constituents in the fuel. At low engine powers (see the left side of Fig. 8a), the aliphatic hydrocarbon (HC) factor makes up the largest fraction of I/SVOC emissions from the aircraft. At $4 \%$ power, the primary mode of aliphatic HCs appears between $\sim 120$ and $130^{\circ} \mathrm{C}$. As the engine power is increased to $7 \%$, the aliphatic $\mathrm{HC}$ emissions shift to slightly higher temperatures (lower volatilities) with a broad peak centered around $\sim 140^{\circ} \mathrm{C}$. The volatility and chemical characteristics of the aliphatic $\mathrm{HC}$ emissions strongly suggest that unburned fuel is the source of these emissions. The slight shift to higher temperatures for the $7 \%$ power compared to the $4 \%$ power may be indicative of fuel fractionation or a transition from unburned fuel emissions to formation of pyrolysis products with the increased temperatures and pressures at $7 \%$ power, but additional study is necessary before definitive conclusions can be drawn. The aliphatic $\mathrm{HC}$ emissions at engine powers $\geq 30 \%$ (see right side of Fig. 8a) are much lower than at engine idle as the overall combustion efficiency of the engine increases at higher powers. At $30 \%$ power, there is a bi-modal volatility distribution with a higher-volatility mode at $\sim 120^{\circ} \mathrm{C}$ and a lower-volatility mode at $\sim 240^{\circ} \mathrm{C}$. The higher-volatility mode is likely unburned fuel, potentially emitted during the transition from $7 \%$ to $30 \%$ power and re-entrained into the $30 \%$ plume. The lower-volatility feature may arise from the formation of larger aliphatic $\mathrm{HC}$ formed via pyrolysis in the higher temperatures and pressures of the combustion process. 
This feature dominates the aliphatic $\mathrm{HC}$ emission profile at $65 \%$ and $85 \%$ power, which exhibit no sign of the volatile unburned fuel mode.

The aromatic factor represents the second-most abundant component of the engine idle exhaust. The aromatic factor mass spectrum with major ion fragments at $\mathrm{m} / \mathrm{z} 55.055$, $67.055,77.039,91.055,105.070$ and 115.055 indicate the presence of unsaturated HCs. This factor also has a very low $\mathrm{O}: \mathrm{C}(0.04)$ but also a low $\mathrm{H}: \mathrm{C}(1.36)$, consistent with aromatic species. The aromatics could have an unburned fuel source (in the case of JP-8 fuel) or be formed via pyrolysis during the combustion process. At $4 \%$ power the aromatic I/SVOC emissions have a primary volatility mode at $\sim 120-130^{\circ} \mathrm{C}$, co-incident with the aliphatic $\mathrm{HC}$ volatility feature attributed to unburned fuel. Since aromatic compounds make up $\sim 25 \%$ of the JP- 8 fuel used here, it follows that such compounds should make up a large fraction of the exhaust at engine idle. The transition from $4 \%$ to $7 \%$ power shows a clear change in volatility of the aromatic I/SVOC emissions resulting in a broad distribution centered around $\sim 190-200^{\circ} \mathrm{C}$. While a high-volatility feature suggesting contributions from unburned fuel is seen in one desorption, the vast majority of aromatic emissions at $7 \%$ power are found in this lower-volatility mode. This suggests that the I/SVOC emissions observed at $7 \%$ power are newly formed products of pyrolysis in aircraft engine, which may be important intermediate species in the formation of soot (which is formed at higher power engine emissions (Onasch et al., 2009). The $30 \%, 65 \%$, and $85 \%$ power aromatic I/SVOC emissions show similar trends as seen with the aliphatic HC emissions, with a bimodal distribution at $30 \%$ power and only the lower-volatility mode present at the higher engine powers.

The oxygenated factor comprises a smaller fraction of the I/SVOC engine idle emissions compared to the aliphatic and aromatic contributions. The major ion fragments in the mass spectrum of the oxygenated factor include $m / z$ 43.018, $44.998,57.070$, and 60.021. This factor has a higher oxygen content than the aliphatic and aromatic factors $(\mathrm{O}: \mathrm{C}=0.26$, $\mathrm{H}: \mathrm{C}=1.46)$. The factor mass spectrum and elemental composition are suggestive of partially oxidized fuel. Consistent with partially oxidized fuel, at $4 \%$ power, the oxygenated factor has a volatile mode between 100 and $110^{\circ} \mathrm{C}$, which is slightly higher in volatility than the volatile aliphatic and aromatic modes. A distinct, low-volatility oxygenated component between 200 and $280{ }^{\circ} \mathrm{C}$ is present for engine powers $\leq 30 \%$. This feature may be indicative of oxidized lubricant or evaporated constituents of POA expected to have lower volatilities. At $30 \%$ power, the oxygenated factor exceeds the aliphatic and aromatic emissions. This observation suggests that the increase in engine power from $7 \%$ to $30 \%$ may have resulted in transient emissions with higher oxygen content. The oxygenated factor includes ion fragments associated with aromatic species $(\mathrm{m} / \mathrm{z}, 77.039,91.055$, and 115.055), suggesting the possible importance of oxygenated

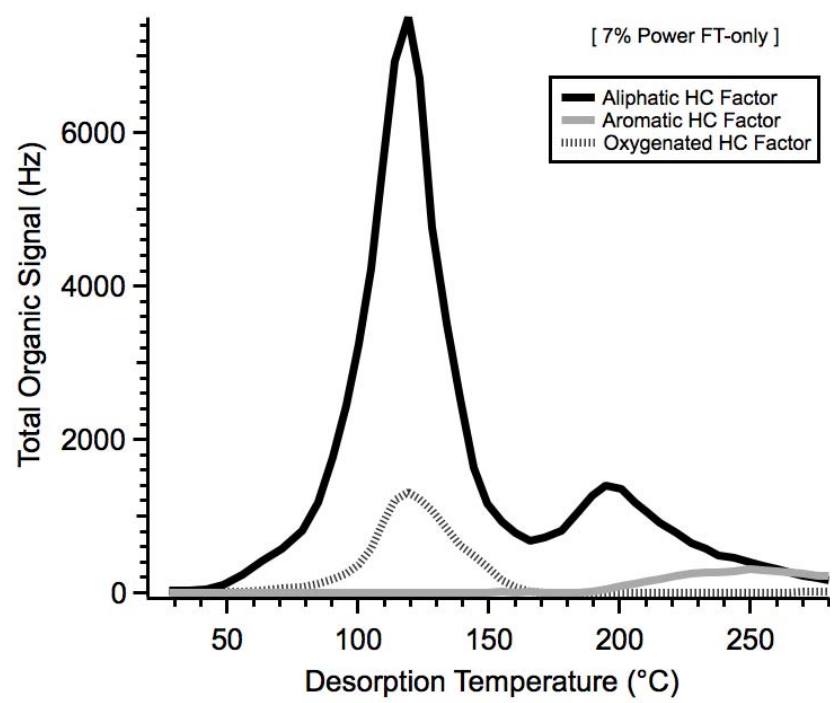

Fig. 9. Desorption profiles of emissions from a single engine burning FT fuel only ( $7 \%$ power). The three PMF factors are the same as shown in Fig. 8.

aromatic species (such as oxygenated PAHs), which might be enhanced during engine power transients. Additional studies are required to further understand the role of oxygenated I/SVOC emissions from aircraft.

\section{6 $7 \%$ Power FT-only emissions}

As mentioned previously, the decrease in $\Delta \mathrm{CO}_{2}$ observed at the transition from $100 \%$ to $7 \%$ power shown in Fig. 4 coincided with a shift in the wind direction, causing only the emissions from E2 (which burned FT fuel) to reach the sampling inlet during that specific collection interval. These measurements thus offer an opportunity to assess the I/SVOC emission profile from the use of FT fuel only (though only at the $7 \%$ power condition). Figure 9 displays the aliphatic, aromatic, and oxygenated factor desorption profiles from this plume. This profile is fundamentally different from the mixed JP-8/FT $7 \%$ power emissions. The aliphatic desorption profile is similar to that observed for aliphatic emissions at $4 \%$ power in the mixed plume, with the highervolatility mode likely due to unburned fuel. The source of the lower-volatility aliphatic compounds could potentially be due to the formation of higher-molecular-weight species in the combustion process. Unlike the idle power mixed plumes, however, a high-volatility (unburned fuel) aromatic factor is absent in the FT-only $7 \%$ plume. Instead, aromatics appear only at the lowest volatilities. This result is fully consistent with expectations, since FT fuel is largely free of aromatic species (Fig. 3) and thus any aromatic emissions from the FT combustion must be formed during the combustion process. Another important feature of the FT-only $7 \%$ power emissions is the prevalence of the oxygenated factor, 
showing a coincident high-volatility mode of the unburned fuel aliphatic signal. This suggests that unburned FT fuel may be a source of oxygenated IVOCs, possibly related to its elevated olefin content. It is likewise noteworthy that the lowvolatility oxygenated feature present in the mixed plumes at $7 \%$ power is absent in the FT-only $7 \%$ plume.

\section{Conclusions}

A novel mass spectrometric instrument was used for in situ measurements of the volatility, mass loading, and bulk chemical composition of I/SVOCs from an aircraft engine operating over a range of power conditions. Total I/SVOC emissions decrease with increasing engine power, with maximum emissions at engine idle. The results provide insight into the sources of I/SVOCs, namely that low-volatility organics are emitted directly as unburned fuel, as pyrolysis products and through processes leading to the formation of oxygenates. The volatility and bulk chemical composition of low-volatility organic emissions at $4 \%$ power suggest that unburned fuel is the dominant source at engine idle operating conditions where $10-20 \%$ of the total hydrocarbon emissions are I/SVOCs. Pyrolysis products constitute a second class of I/SVOC emissions and comprise an important fraction of total gas-phase organic emissions at engine powers $\geq 7 \%$. This observation is broadly consistent with powerdependent VOC emissions which have been shown to shift from primarily fuel cracking products (predominately unsaturated hydrocarbons) to pyrolysis products at powers $\geq 30 \%$ (Anderson et al., 2006; Beyersdorf et al., 2012). The role of aromatic I/SVOC species as intermediates in the formation of soot remains poorly understood, but these measurements present some of the first in situ evidence of gas-phase intermediates to soot formation. Oxygenated I/SVOC emissions were detected at engine powers $\leq 30 \%$ and may be linked to cracked, partially oxidized or unburned fuel components. Two distinct volatility modes for oxygenated I/SVOCs were observed in the mixed JP-8/FT plume. Given the higher degree of oxidation and lower initial volatility of oxygenated I/SVOCs, such emissions could result in higher secondary organic aerosol yields downwind of airport terminals. Continued efforts to characterize I/SVOC emissions from aircraft, spanning a wider range of engine types, fuel types, operating parameters, and environmental conditions, are needed to better understand both the air quality and climate implications of this important class of combustion-derived organics.

\section{Supplementary material related to this article is available online at: http://www.atmos-chem-phys.net/13/ 7845/2013/acp-13-7845-2013-supplement.pdf.}

Acknowledgements. NASA led the AAFEX-II mission and the Dryden Aircraft Operations Facility (DAOF) graciously hosted the emissions measurements described here. The experiments described in this manuscript were possible due to contributions from Bruce Anderson, Andreas Beyersdorf and Luke Ziemba (NASA Langley); John Kinsey (U.S. EPA); Robert Howard (U.S. Air Force, Arnold Engineering Design Center); Edwin Corporan (Air Force Research Laboratory); Matt DeWitt (University of Dayton, Research Institute); Dave Liscinsky (United Technologies); Anuj Bhargava (Pratt \& Whitney); and Phil Whitefield, Don Hagen, and Prem Lobo (Missouri University of Science and Technology). The authors also gratefully acknowledge Brent Williams and Nathan Kreisberg for aid in the initial development of the collection/desorption cell, Changlie Wey (NASA Langley) for providing the $1 \mathrm{~m}$ THC data, Luke Ziemba, Andreas Beyersdorf and Bruce Anderson for helpful discussions or aircraft exhaust chemical composition, Mike Timko (Aerodyne Research, Inc.) for providing fuel samples and helpful discussions, Manjula Canagaratna and Donna Sueper (Aerodyne Research, Inc.) for helpful discussions regarding PMF and high-resolution data analysis procedures, Katrin Fuhrer and Marc Gonin (TOFWERK, AG) for hardware support, and NOAA for use of their sampling trailer. This research was supported by the DOE SBIR program (grant DE-SC0001666) and the EPA STAR program through the National Center for Environmental Research (NCER) under grant RD834560. This paper has not been subject to EPA-required peer and policy review, and therefore does not necessarily reflect the views of the Agency. No official endorsement should be inferred. E. S. Cross was supported by the Camille and Henry Dreyfus Postdoctoral Program in Environmental Chemistry.

Edited by: P. Monks

\section{References}

Agrawal, H., Sawant, A. A., Jansen, K., Wayne Miller, J., and Cocker III, D. R.: Characterization of chemical and particulate emissions from aircraft engines, Atmos. Environ., 42, 43804392, doi:10.1016/j.atmosenv.2008.01.069, 2008.

Aiken, A. C., DeCarlo, P. F., and Jimenez, J. L.: Elemental analysis of organic species with electron ionization highresolution mass spectrometry, Anal. Chem., 79, 8350-8358, doi:10.1021/ac071150w, 2007.

Aiken, A. C., DeCarlo, P. F., Kroll, J. H., Worsnop, D. R., Huffman, J. A., Docherty, K. S., Ulbrich, I. M., Mohr, C., Kimmel, J. R., Sueper, D., Sun, Y., Zhang, Q., Trimborn, A., Northway, M., Ziemann, P. J., Canagaratna, M. R., Onasch, T. B., Alfarra, M. R., Prevot, A. S. H., Dommen, J., Duplissy, J., Metzger, A., Baltensperger, U., and Jimenez, J. L.: O/C and OM/OC ratios of primary, secondary, and ambient organic aerosols with highresolution time-of-flight aerosol mass spectrometry, Environ. Sci. Technol., 42, 4478-4485, doi:10.1021/es703009q, 2008.

Anderson, B. E., Chen, G., and Blake, D. R.: Hydrocarbon emissions from a modern commercial airliner, Atmos. Environ., 40, 3601-3612, doi:10.1016/j.atmosenv.2005.09.072, 2006.

Arunachalam, S., Wang, B., Davis, N., Baek, B. H., and Levy, J. I.: Effect of chemistry-transport model scale and resolution on population exposure to $\mathrm{PM}_{2.5}$ from aircraft emissions dur- 
ing landing and takeoff, Atmos. Environ., 45, 3294-3300, doi:10.1016/j.atmosenv.2011.03.029, 2011.

Beyersdorf, A. J., Thornhill, K. L., Winstead, E. L., Ziemba, L. D., Blake, D. R., Timko, M. T., and Anderson, B. E.: Power-dependent speciation of volatile organic compounds in aircraft exhaust, Atmos. Environ., 61, 275-282, doi:10.1016/j.atmosenv.2012.07.027, 2012.

Canagaratna, M. R., Jayne, J. T., Jimenez, J. L., Allan, J. D., Alfarra, M. R., Zhang, Q., Onasch, T. B., Drewnick, F., Coe, H., Middlebrook, A., Delia, A., Williams, L. R., Trimborn, A. M., Northway, M. J., DeCarlo, P. F., Kolb, C. E., Davidovits, P., and Worsnop, D. R.: Chemical and microphysical characterization of ambient aerosols with the aerodyne aerosol mass spectrometer, Mass Spectrom. Rev., 26, 185-222, doi:10.1002/mas.20115, 2007.

DeCarlo, P. F., Kimmel, J. R., Trimborn, A., Northway, M. J., Jayne, J. T., Aiken, A. C., Gonin, M., Fuhrer, K., Horvath, T., Docherty, K. S., Worsnop, D. R., and Jimenez, J. L.: Fielddeployable, high-resolution, time-of-flight aerosol mass spectrometer, Anal. Chem., 78, 8281-8289, doi:10.1021/ac061249n, 2006.

FAA: FAA Aerospace Forecast Fiscal Years 2010-2030, available at: http://www.faa.gov/data_research/aviation/aerospace forecasts/2010-2030/, last access: 22 February 2013.

Herndon, S. C., Rogers, T., Dunlea, E. J., Jayne, J. T., MiakeLye, R., and Knighton, B.: Hydrocarbon emissions from inuse commercial aircraft during airport operations, Environ. Sci. Technol., 40, 4406-4413, doi:10.1021/es0512091, 2006.

Herndon, S. C., Wood, E. C., Northway, M. J., Miake-Lye, R., Thornhill, L., Beyersdorf, A., Anderson, B. E., Dowlin, R., Dodds, W., and Knighton, W. B.: Aircraft hydrocarbon emissions at Oakland International Airport, Environ. Sci. Technol., 43, 1730-1736, doi:10.1021/es801307m, 2009.

Hsu, H.-H., Adamkiewicz, G., Houseman, E. A., Vallarino, J., Melly, S. J., Wayson, R. L., Spengler, J. D., and Levy, J. I.: The relationship between aviation activities and ultrafine particulate matter concentrations near a mid-sized airport, Atmos. Environ., 50, 328-337, doi:10.1016/j.atmosenv.2011.12.002, 2012.

Jayne, J. T., Leard, D. C., Zhang, X., Davidovits, P., Smith, K. A., Kolb, C. E., and Worsnop, D. R.: Development of an aerosol mass spectrometer for size and composition analysis of submicron particles, Aerosol Sci. Technol., 33, 49-70, 2000.

Knighton, W. B., Rogers, T. M., Anderson, B. E., Herndon, S. C., Yelvington, P. E., and Miake-Lye, R. C.: Quantification of aircraft engine hydrocarbon emissions using proton transfer reaction mass spectrometry, J. Propulsion, 23, 949-958, doi:10.2514/1.22965, 2007.

Kolb, C. E., Herndon, S. C., McManus, J. B., Shorter, J. H., Zahniser, M. S., Nelson, D. D., Jayne, J. T., Canagaratna, M. R., and Worsnop, D. R.: Mobile laboratory with rapid response instruments for real-time measurements of urban and regional trace gas and particulate distributions and emission source characteristics, Environ. Sci. Technol., 38, 5694-5703, doi:10.1021/es030718p, 2004.

Lanz, V. A., Alfarra, M. R., Baltensperger, U., Buchmann, B., Hueglin, C., and Prévôt, A. S. H.: Source apportionment of submicron organic aerosols at an urban site by factor analytical modelling of aerosol mass spectra, Atmos. Chem. Phys., 7, 15031522, doi:10.5194/acp-7-1503-2007, 2007.
Levy, J. I., Woody, M., Baek, B. H., Shankar, U., and Arunachalam, S.: Current and future particulate-matter-related mortality risks in the United States from aviation emissions during landing and takeoff, Risk Anal., 32, 237-249, doi:10.1111/j.15396924.2011.01660.x, 2011.

Miracolo, M. A., Hennigan, C. J., Ranjan, M., Nguyen, N. T., Gordon, T. D., Lipsky, E. M., Presto, A. A., Donahue, N. M., and Robinson, A. L.: Secondary aerosol formation from photochemical aging of aircraft exhaust in a smog chamber, Atmos. Chem. Phys., 11, 4135-4147, doi:10.5194/acp-11-4135-2011, 2011.

Miracolo, M. A., Drozd, G. T., Jathar, S. H., Presto, A. A., Lipsky, E. M., Corporan, E., and Robinson, A. L.: Fuel composition and secondary organic aerosol formation: gas-turbine exhaust and alternative aviation fuels, Environ. Sci. Technol., 46, 8493-8501, doi:10.1021/es300350c, 2012.

Onasch, T. B., Jayne, J. T., Herndon, S., Worsnop, D. R., MiakeLye, R. C., Mortimer, I. P., and Anderson, B. E.: Chemical properties of aircraft engine particulate exhaust emissions, J. Propulsion, 25, 1121-1137, doi:10.2514/1.36371, 2009.

Paatero, P. and Tapper, U.: Positive matrix factorization: a nonnegative factor model with optimal utilization of error estimates of data values, Environmetrics, 5, 111-126, 1994.

Presto, A. A., Nguyen, N. T., Ranjan, M., Reeder, A. J., Lipsky, E. M., Hennigan, C. J., Miracolo, M. A., Riemer, D. D., and Robinson, A. L.: Fine particle and organic vapor emissions from staged tests of an in-use aircraft engine, Atmos. Environ., 45, 3603-3612, doi:10.1016/j.atmosenv.2011.03.061, 2011.

Presto, A. A., Hennigan, C. J., Nguyen, N. T., and Robinson, A. L.: Determination of volatility distributions of primary organic aerosol emissions from internal combustion engines using thermal desorption gas chromatography mass spectrometry, Aerosol Sci. Technol., 46, 1129-1139, doi:10.1080/02786826.2012.700430, 2012.

Robinson, A. L., Donahue, N. M., Shrivastava, M. K., Weitkamp, E. A., Sage, A. M., Grieshop, A. P., Lane, T. E., Pierce, J. R., and Pandis, S. N.: Rethinking organic aerosols: semivolatile emissions and photochemical aging, Science, 315, 1259-1262, doi:10.1126/science.1133061, 2007.

Robinson, A. L., Grieshop, A. P., Donahue, N. M., and Hunt, S. W.: Updating the Conceptual Model for Fine Particle Mass Emissions from Combustion Systems Allen L. Robinson, J. Air Waste Manage. Assoc., 60, 1204-1222, doi:10.3155/10473289.60.10.1204, 2010.

Slemr, F., Giehl, H., Slemr, J., Busen, R., Schulte, P., and Haschberger, P.: In-flight measurement of aircraft non-methane hydrocarbon emission indices, Geophys. Res. Lett., 25, 321-324, 1998.

Slemr, F., Giehl, H., Habram, M., Slemr, J., Schlager, H., Schulte, P., Haschberger, P., Lindermeir, E., Dopelheuer, A., and Plohr, M.: In-flight measurement of aircraft $\mathrm{CO}$ and nonmethane hydrocarbon emission indices, J. Geophys. Res.-Atmos., 106, 7485-7494, 2001.

Spicer, C. W., Holdren, M. W., Smith, D. L., Hughes, D. P., and Smith, M. D.: Chemical composition of exhaust from aircraft turbine engines, J. Eng. Gas Turb. Power, 114, 111, doi:10.1115/1.2906292, 1992.

Spicer, C. W., Holdren, M. W., Riggin, R. M., and Lyon, T. F.: Chemical composition and photochemical reactivity of exhaust from aircraft turbine engines, Ann. Geophys., 12, 944-955, 
doi:10.1007/s00585-994-0944-0, 1994.

Stettler, M. E. J., Eastham, S., and Barrett, S. R. H.: Air quality and public health impacts of UK airports - Part I: emissions, Atmos. Environ., 45, 5415-5424, doi:10.1016/j.atmosenv.2011.07.012, 2011.

Timko, M. T., Onasch, T. B., Northway, M. J., Jayne, J. T., Canagaratna, M. R., Herndon, S. C., Wood, E. C., Miake-Lye, R. C., and Knighton, W. B.: Gas turbine engine emissions - Part II: Chemical properties of particulate matter, J. Eng. Gas. Turb. Power, 132, 06150, doi:10.1115/1.4000132, 2010a.

Timko, M. T., Yu, Z., Onasch, T. B., Wong, H. W., Miake-Lye, R. C., Beyersdorf, A. J., Anderson, B. E., Thornhill, K. L., Winstead, E. L., Corporan, E., DeWitt, M. J., Klingshirn, C. D., Wey, C., Tacina, K., Liscinsky, D. S., Howard, R., and Bhargava, A.: Particulate emissions of gas turbine engine combustion of a Fischer-Tropsch synthetic Fuel, Energ. Fuel., 24, 5883-5896, doi:10.1021/ef100727t, 2010b.

Ulbrich, I. M., Canagaratna, M. R., Zhang, Q., Worsnop, D. R., and Jimenez, J. L.: Interpretation of organic components from Positive Matrix Factorization of aerosol mass spectrometric data, Atmos. Chem. Phys., 9, 2891-2918, doi:10.5194/acp-9-2891-2009, 2009.

Unal, A., Hu, Y., Chang, M. E., Talat Odman, M., and Russell, A. G.: Airport related emissions and impacts on air quality: application to the Atlanta International Airport, Atmos. Environ., 39, 5787-5798, doi:10.1016/j.atmosenv.2005.05.051, 2005.

Unger, N.: Global climate impact of civil aviation for standard and desulfurized jet fuel, Geophys. Res. Lett., 38, L20803, doi:10.1029/2011GL049289, 2011.
Wey, C. C., Anderson, B. E., Wey, C., Miake-Lye, R. C., Whitefield, P. D., and Howard, R.: Overview on the aircraft particle emissions experiment, J. Propulsion, 23, 898-905, 2007.

Williams, P. I., Allan, J. D., Lobo, P., Coe, H., Christie, S., Wilson, C., Hagen, D., Whitefield, P., Raper, D., and Rye, L.: Impact of alternative fuels on emissions characteristics of a gas turbine engine - Part 2: Volatile and semivolatile particulate matter emissions, Environ. Sci. Technol., 46, 10812-10819, doi:10.1021/es301899s, 2012.

Yelvington, P. E., Herndon, S. C., Wormhoudt, J. C., Jayne, J. T., Miake-Lye, R. C., Berk Knighton, W., and Wey, C.: Chemical speciation of hydrocarbon emissions from a commercial aircraft engine, J. Propulsion, 23, 912-918, doi:10.2514/1.23520, 2007.

Yu, Z., Liscinsky, D. S., Winstead, E. L., True, B. S., Timko, M. T., Bhargava, A., Herndon, S. C., Miake-Lye, R. C., and Anderson, B. E. Characterization of Lubrication Oil Emissions from Aircraft Engines, Environ. Sci. Technol., 44, 9530-9534, doi:10.1021/es102145z, 2010.

Yu, Z., Herndon, S. C., Ziemba, L. D., Timko, M. T., Liscinsky, D. S., Anderson, B. E., and Miake-Lye, R. C.: Identification of Lubrication Oil in the Particulate Matter Emissions from Engine Exhaust of In-Service Commercial Aircraft, Environ. Sci. Technol., 46, 9630-9637, doi:10.1021/es301692t, 2012.

Zhang, Q., Jimenez, J. L., Canagaratna, M. R., Ulbrich, I. M., Ng, N. L., Worsnop, D. R., and Sun, Y.: Understanding atmospheric organic aerosols via factor analysis of aerosol mass spectrometry: a review, Anal. Bioanal. Chem., 401, 3045-3067, doi:10.1007/s00216-011-5355-y, 2011. 